\title{
Effect of CYP2C9*3 mutant variants on meloxicam pharmacokinetics in a healthy Chinese population
}

\author{
M. Zhang, Y. Yang, G. Zhao, X. Di, L. Xu, N. Jiang, J. Xu and X. Xu \\ Department of Pharmacology, the Military General Hospital of Beijing PLA, \\ Beijing, China \\ Corresponding author: M. Zhang \\ E-mail: may1008_zhang@yeah.net
}

Genet. Mol. Res. 13 (1): 831-837 (2014)

Received December 5, 2012

Accepted November 20, 2013

Published February 13, 2014

DOI http://dx.doi.org/10.4238/2014.February.13.1

\begin{abstract}
The aim of this study was to investigate the effect of the CYP2C9*3 (CYP2C9 $1075 \mathrm{~A}>\mathrm{C}$ ) polymorphism on meloxicam pharmacokinetics in a Chinese population. Twenty-four healthy volunteers were enrolled in this study. The pyrosequencing technique was used to identify polymorphisms of CYP2C9. The concentration of meloxicam in plasma was determined by a high-performance liquid chromatography assay with mass spectrographic analysis. The Drug and Statistics Software (DAS, version 2.0) was used for curve fitting and calculations of pharmacokinetic parameters. The effects of CYP2C9*3 variant genotypes on meloxicam pharmacokinetics were compared with those of the wild type genotype. Among the 24 volunteers, two AC heterozygotes were observed in the multi-dose group. CYP2C $9 * 3$ was found to play an important role in the metabolism of meloxicam by reducing its enzymatic activity. Therefore, results of this study provide helpful information regarding inter-individual pharmacokinetic variability in the Chinese population.
\end{abstract}

Key words: Meloxicam; CYP2C9; Single nucleotide polymorphism; Genotyping 


\section{INTRODUCTION}

Meloxicam is a new non-steroidal anti-inflammatory drug (NSAID) that is effective for the treatment of rheumatoid arthritis and osteoarthritis. In mammals, meloxicam is mainly converted to a 5-hydroxymethyl metabolite by the enzyme CYP2C9 (Schmid et al., 1995; Chesne et al., 1998). Thirty-five different types of CYP2C9 alleles have been reported to date (http://www.cypalleles.ki.se/cyp2c9.htm), of which CYP2C9*2 and CYP2C9*3 were the most frequently identified in most populations (Bae et al., 2011a). Individuals with CYP2C9 variant genotypes may not metabolize drugs adequately, resulting in changes in drug toxicity. Changes in amino acid sequences of CYP2C9 can affect both its activity and substrate specificity (van der Weide et al., 2001; Miners, 2002). Therefore, drug doses must be adjusted according to the individual's genotype.

The frequencies of CYP2C9 mutants show high inter-individual variability across different populations. In the Chinese population, CYP2C $9 * 3$ is a major allele, in which the nucleotide A is replaced by C (A 1075 to C substitution) in exon 7 (Wang et al., 1995; Yoon et al., 2001). In this study, we aimed to investigate the effects of the CYP2C $* 3$ variant genotype on meloxicam pharmacokinetics in a Chinese population. To our knowledge, this is the first report to examine this relationship.

\section{MATERIAL AND METHODS}

\section{Subjects}

Twenty-four healthy volunteers (males: 12, females: 12; with an average age of 27.3 \pm 2.9 years) were randomly divided into a single dose group $(\mathrm{N}=12,7.5 \mathrm{mg}$ meloxicam via intramuscular injection) and a multi-dose group $(\mathrm{N}=12,15 \mathrm{mg}$ meloxicam per day, via intramuscular injection, for 8 days). Meloxicam, with a purity of $99.8 \%$, was purchased from the National Institutes for Food and Drug Control, Beijing, China. All volunteers were deemed healthy according to their medical history, physical examination, and routine laboratory tests (i.e. blood chemistry, hematology, and urine test). All subjects refrained from participating in any clinical medication tests within the 2 months prior to the study. In addition, the volunteers refrained from taking any medication prior to the study. Written informed consent was obtained from each volunteer before the study. The study was performed in compliance with the guidelines of the Declaration of Helsinki, and was approved by the ethics committee of the Military General Hospital of Beijing PLA.

\section{Study protocol}

For the single dose group, each patient was injected with $7.5 \mathrm{mg}$ meloxicam. For the multi-dose group, $15 \mathrm{mg}$ meloxicam was injected via intramuscular injection for 8 consecutive days. Patients were maintained in a fasting state for $4 \mathrm{~h}$ after administration of the drug. Venous blood samples $(2.5 \mathrm{~mL})$ were obtained before and at $0.25,0.5,0.75,1,1.5,2,4,7,12,24$, 48,72 , and $96 \mathrm{~h}$ after meloxicam administration. Pharmacokinetic parameters of meloxicam were estimated using non-compartmental methods. The corresponding parameters, including maximum plasma concentration (Cmax), the area under the plasma concentration-time curve 
(AUC), and the apparent oral clearance $(\mathrm{CL} / \mathrm{F})$ of meloxicam, were calculated according to previously described methods [8]. Blood samples were centrifuged immediately after collection and plasma samples were stored at $-70^{\circ} \mathrm{C}$.

\section{Meloxicam plasma concentration}

The plasma concentration of melcoxicam was determined by a high-performance liquid chromatography (HPLC) assay with mass spectrographic (MS) analysis with slight modifications. In brief, $100 \mu \mathrm{L}$ plasma was spiked with $20 \mu \mathrm{L}$ internal standard (piroxicam, purchased from the National Institutes for Food and Drug Control, Beijing, China), acidified with $5 \mathrm{M} \mathrm{HCl}$, followed by extraction with $2 \mathrm{~mL}$ diethyl ether. A $10-\mu \mathrm{L}$ aliquot was added to the analytical column (Thermo/Hypersil ${ }^{\circledR}$ BetaBasic C8, $5 \mu \mathrm{m}, 100 \times 2.1 \mathrm{~mm}$, Thermo Fisher Scientific Inc., Waltham, MA, USA). The mobile phase was formed by a mixture of $0.3 \%$ formic acid and $20 \mathrm{mM}$ ammonium formate $(\mathrm{v}: \mathrm{v}=70: 30, \mathrm{pH}=6.5)$. The flow rate was set to $0.2 \mathrm{~mL} / \mathrm{min}$. The column temperature was $25^{\circ} \mathrm{C}$. Mass spectrum analysis was performed using target ions at $\mathrm{m} / \mathrm{z} 352 \rightarrow \mathrm{m} / \mathrm{z} 115$ for meloxicam and $\mathrm{m} / \mathrm{z} 332 \rightarrow$ $\mathrm{m} / \mathrm{z} 95$ for piroxicam. The detection limit of meloxicam was $20 \mathrm{ng} / \mathrm{mL}$. The linear range of the standard curve for plasma meloxicam was from 20 to $5000 \mathrm{ng} / \mathrm{mL}$ ( $\mathrm{Y}=0.0224757$ $+0.00501004 \mathrm{X}, \mathrm{R}^{2}=0.9997$ ).

\section{Genotyping of CYP2C9}

For CYP2C9 genotype detection, $3 \mathrm{~mL}$ whole blood from a peripheral vein was drawn into an ethylenediaminetetraacetic acid tube. Genomic DNA was isolated using the TIANamp Genomic DNA Kit (Tiangen Biotech Co., Ltd., Beijing, China). The CYP2C9 1075 A $>$ C genetic polymorphism was detected by polymerase chain reaction (PCR) and the PyroMark pyrosequencing technique. The forward primer was 5'-CCTGC ATGCAAGACAGGA-3' and the reverse primer was 5'-GAATTTGGGGACTTCGAAAA-3'. The sequencing primer was 5'-TGGGGAGAAGGTCAA-3'. PCR was performed in a total volume of $50 \mu \mathrm{L}$, including 10X $5 \mu \mathrm{L}$ PCR buffer, $25 \mathrm{mM} 3 \mu \mathrm{L} \mathrm{MgCl}, 10 \mathrm{Mm} 0.5 \mu \mathrm{L}$ dNTP, $1 \mu \mathrm{L}$ each forward and reverse primer, $5 \mathrm{U} / \mu \mathrm{L} 0.2 \mu \mathrm{L}$ Taq DNA polymerase (Sangon Biotech Co., Ltd, Shanghai, China), and $1 \mu \mathrm{L}$ DNA template. Amplification was performed using a Biometra TPersonal Thermal Cycler (Biometra $\mathrm{GmbH}$, Goettingen, Germany) by initial denaturation at $95^{\circ} \mathrm{C}$ for $3 \mathrm{~min}$, followed by $45 \mathrm{cycles}$, including denaturation at $95^{\circ} \mathrm{C}$ for $30 \mathrm{~s}$, annealing at $57^{\circ} \mathrm{C}$ for $30 \mathrm{~s}$, and extension at $72^{\circ} \mathrm{C}$ for $15 \mathrm{~s}$. A final extension followed at $72^{\circ} \mathrm{C}$ for $3 \mathrm{~min}$. DNA sequencing detection was performed using the PyroMark ID system (QIAGEN Co., Ltd., Shanghai, China).

\section{Statistical analysis}

Curve fitting was performed using the Drug and Statistics Software (DAS), version 2.0. The plasma concentration-time curve conformed to the two-compartment model, from which Cmax and the time to reach Cmax (tmax) were calculated. A one-way analysis of variance (ANOVA) was conducted in the single dose group to determine statistical significance of the difference in parameters. The Student's $t$-test was conducted for the multi-dose group to 
assess differences in AUC and Cmax between day 1 and 8, respectively. $\mathrm{P}<0.05$ demonstrated a significant statistical difference.

\section{RESULTS}

All volunteers accomplished the study in compliance with the proposed study protocol. No abnormal clinical signs or manifestations were observed after single or multidose administration. The PCR products were electrophoresed on $2 \%$ agarose gel. DNA sequencing was detected by the PyroMark ID system (QIAGEN). The sequencing results were consistent with the DNA sequence detected using the ABI automatic sequencer (Applied Biosystems Inc., Foster City, CA, USA) as shown in Figure 1. Only the wild type, CYP2C9 $1075 \mathrm{~A} / \mathrm{A}$, was detected among the 12 subjects in the single-dose group. Pharmacokinetics after a single $7.5 \mathrm{mg}$ meloxicam administration in the 12 subjects are listed in Table 1. In the multi-dose group, CYP2C9 $1075 \mathrm{~A} / \mathrm{C}$ heterozygotes were detected in two volunteers $(16.7 \%$, Table 2$)$.

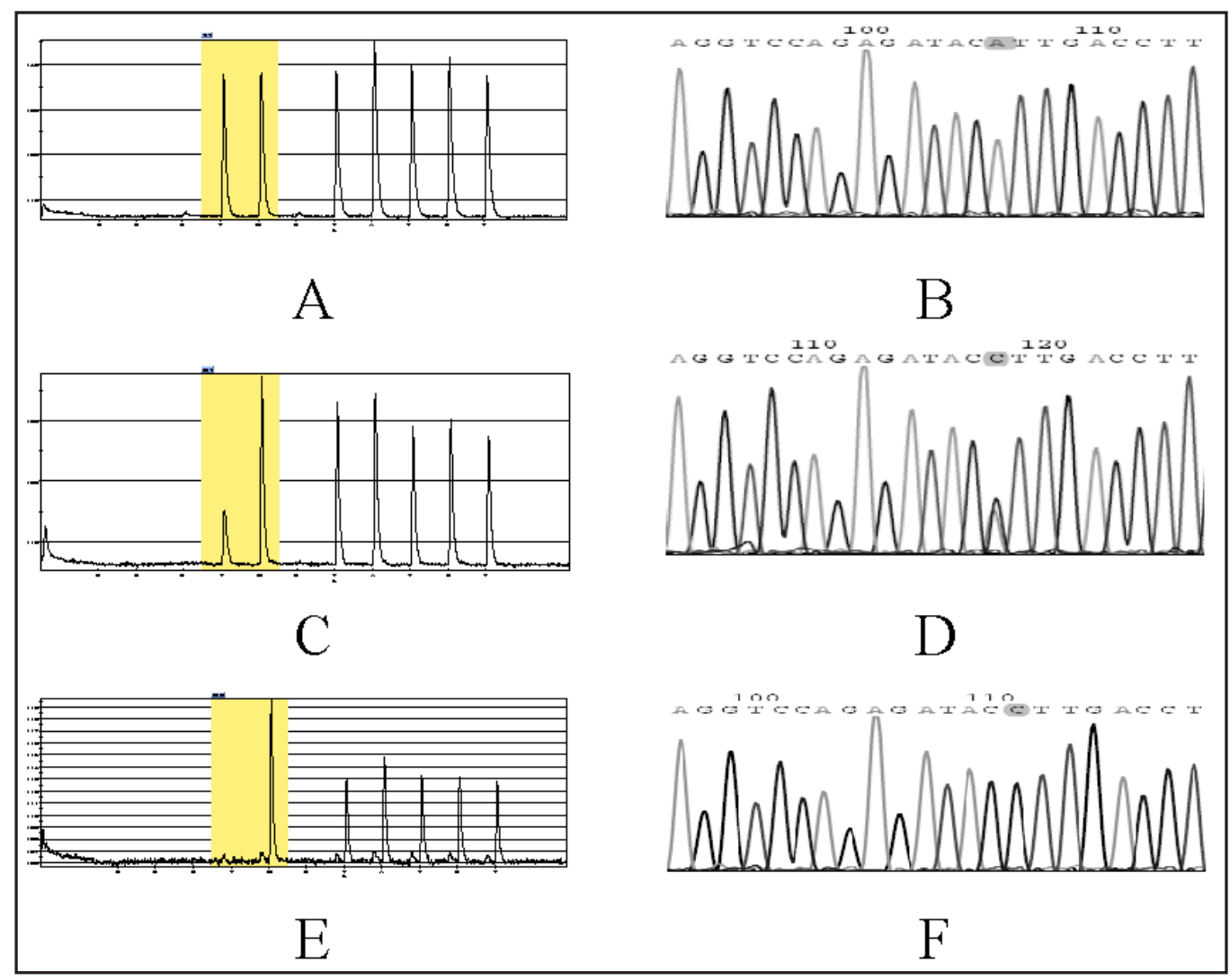

Figure 1. A. Pyrosequencing results for wild type of CYP2C9*3 (A/A) B. DNA sequencing using ABI system for wild type of CYP2C $9 * 3$ C. Pyrosequencing results for heterozygote type of CYP2C9*3 (A/C) D. DNA sequencing using $\mathrm{ABI}$ system for heterozygote type $\mathrm{CYP} 2 \mathrm{C} 9 * 3 \mathbf{E}$. Pyrosequencing results for homozygote type of CYP2CP*3 (C/C) F. DNA sequencing using ABI system for homozygote type of CYP2C9*3. 


\begin{tabular}{|c|c|c|c|c|}
\hline \multirow[t]{2}{*}{ ID } & \multirow{2}{*}{$\begin{array}{c}\text { Genotype } \\
\text { CYP2C9 } 1075 \mathrm{~A}>\mathrm{C}\end{array}$} & \multicolumn{3}{|c|}{ Single dose group $(7.5 \mathrm{mg})$} \\
\hline & & $\mathrm{Cmax}(\mathrm{ng} / \mathrm{mL})$ & $\operatorname{AUC}(0-\mathrm{t})(\mathrm{ng} \cdot \mathrm{h} / \mathrm{mL})$ & $\mathrm{CL} / \mathrm{F}(\mathrm{L} / \mathrm{h})$ \\
\hline 1 & $\mathrm{~A} / \mathrm{A}$ & 1073.6 & 22333.3 & 0.328 \\
\hline 2 & $\mathrm{~A} / \mathrm{A}$ & 1677.2 & 32477.1 & 0.227 \\
\hline 3 & $\mathrm{~A} / \mathrm{A}$ & 1167.1 & 28096.9 & 0.249 \\
\hline 4 & $\mathrm{~A} / \mathrm{A}$ & 1045.3 & 26926.0 & 0.271 \\
\hline 5 & $\mathrm{~A} / \mathrm{A}$ & 1070.4 & 32085.1 & 0.220 \\
\hline 6 & $\mathrm{~A} / \mathrm{A}$ & 857.9 & 15034.1 & 0.475 \\
\hline 7 & $\mathrm{~A} / \mathrm{A}$ & 567.3 & 11706.4 & 0.572 \\
\hline 8 & $\mathrm{~A} / \mathrm{A}$ & 697.0 & 17525.3 & 0.408 \\
\hline 9 & $\mathrm{~A} / \mathrm{A}$ & 744.8 & 27365.1 & 0.259 \\
\hline 10 & $\mathrm{~A} / \mathrm{A}$ & 845.5 & 23175.8 & 0.302 \\
\hline 11 & $\mathrm{~A} / \mathrm{A}$ & 826.0 & 21024.3 & 0.337 \\
\hline 12 & $\mathrm{~A} / \mathrm{A}$ & 1016.2 & 23870.6 & 0.290 \\
\hline $\mathrm{X}$ & - & 965.7 & 23468.3 & 0.328 \\
\hline SD & - & 286.6 & 6440.5 & 0.107 \\
\hline
\end{tabular}

\begin{tabular}{|c|c|c|c|c|c|c|c|}
\hline \multirow[t]{2}{*}{ ID } & \multirow{2}{*}{$\frac{\text { Genotype }}{2 \text { CYP2C9 } 1075 \mathrm{~A}>\mathrm{C}}$} & \multicolumn{3}{|c|}{ Parameters on day 1} & \multicolumn{3}{|c|}{ Parameters on day 8} \\
\hline & & $\mathrm{Cmax}(\mathrm{ng} / \mathrm{mL})$ & $\mathrm{AUC}(0-\mathrm{t})(\mathrm{ng} \cdot \mathrm{h} / \mathrm{mL})$ & $\mathrm{CL} / \mathrm{F}(\mathrm{L} / \mathrm{h})$ & $\mathrm{Cmax}(\mathrm{ng} / \mathrm{mL})$ & $\operatorname{AUC}(0-\mathrm{t})(\mathrm{ng} \cdot \mathrm{h} / \mathrm{mL})$ & $\mathrm{CL} / \mathrm{F}(\mathrm{L} / \mathrm{h})$ \\
\hline 1 & $\mathrm{~A} / \mathrm{A}$ & 2707.8 & 68364.7 & 0.207 & 2864.6 & 91731.0 & 0.155 \\
\hline 2 & $\mathrm{~A} / \mathrm{A}$ & 2785.2 & 62667.5 & 0.233 & 2845.7 & 70101.2 & 0.208 \\
\hline 3 & $\mathrm{~A} / \mathrm{A}$ & 2332.3 & 49745.8 & 0.289 & 2977.7 & 104484.4 & 0.134 \\
\hline 4 & $\mathrm{~A} / \mathrm{A}$ & 1967.2 & 47656.4 & 0.303 & 2315.8 & 83171.6 & 0.172 \\
\hline 5 & $\mathrm{~A} / \mathrm{C}$ & 1928.8 & 78966.0 & 0.155 & 4559.8 & 206065.5 & 0.060 \\
\hline 6 & $\mathrm{~A} / \mathrm{A}$ & 1905.8 & 54387.1 & 0.242 & 3314.8 & 123797.6 & 0.101 \\
\hline 7 & $\mathrm{~A} / \mathrm{A}$ & 1217.8 & 31040.2 & 0.455 & 2260.9 & 79268.8 & 0.176 \\
\hline 8 & $\mathrm{~A} / \mathrm{A}$ & 2121.5 & 56557.6 & 0.239 & 2317.5 & 90589.6 & 0.151 \\
\hline 9 & $\mathrm{~A} / \mathrm{C}$ & 1808.3 & 77064.5 & 0.158 & 4245.7 & 216227.8 & 0.058 \\
\hline 10 & $\mathrm{~A} / \mathrm{A}$ & 1966.1 & 62578.3 & 0.271 & 2722.5 & 103958.4 & 0.137 \\
\hline 11 & $\mathrm{~A} / \mathrm{A}$ & 1486.5 & 33020.1 & 0.437 & 1664.0 & 49721.3 & 0.284 \\
\hline 12 & $\mathrm{~A} / \mathrm{A}$ & 2334.7 & 47915.5 & 0.302 & 2444.2 & 83952.7 & 0.163 \\
\hline $\mathrm{X}$ & - & 2046.8 & 55830.3 & 0.270 & 2877.7 & 108589.2 & 0.150 \\
\hline SD & - & 452.9 & 15194.2 & 0.095 & 831.1 & 51367.6 & 0.063 \\
\hline
\end{tabular}

As shown in Table 3, after the first administration day for the multi-dose group, no statistical difference was noted in $\mathrm{Cmax}, \mathrm{AUC}(0-\mathrm{t})$, or $\mathrm{CL} / \mathrm{F}$ between the wild type and CYP2C $9 * 3$ variant genotypes $(\mathrm{P}>0.05)$. After consecutive administrations (8 days), the mean AUC $(0-\mathrm{t})$ of meloxicam in CYP2C $9 * 1 / * 3(1075 \mathrm{~A} / \mathrm{C})$ subjects was 2.40 -fold higher than those of the wild type $(\mathrm{P}<0.05)$. The $\mathrm{CL}$ of meloxicam in subjects with the mutant type was 2.89 -fold higher than those of the wild type on day $8(\mathrm{P}<0.05)$. Similarly, the Cmax in subjects with the mutant type was 1.71-fold higher than those of the wild type on day $8(\mathrm{P}<0.05)$.

\begin{tabular}{|c|c|c|c|c|}
\hline \multirow[t]{2}{*}{ Parameters } & \multicolumn{2}{|c|}{ Multi-dose group (day 1) } & \multicolumn{2}{|c|}{ Multi-dose group (day 8) } \\
\hline & $\mathrm{A} / \mathrm{A}$ & $\mathrm{A} / \mathrm{C}$ & $\mathrm{A} / \mathrm{A}$ & $\mathrm{A} / \mathrm{C}$ \\
\hline AUC (ng.h/ml) & $51393.3 \pm 646.8$ & $78015.3 \pm 950.8$ & $88077.7 \pm 19313.2$ & $211146.7 \pm 5081.2$ \\
\hline $\mathrm{Cmax}(\mathrm{ng} / \mathrm{ml})$ & $2082.5 \pm 466.2$ & $1868.5 \pm 60.3$ & $2572.8 \pm 443.6$ & $4402.8 \pm 157.1$ \\
\hline $\mathrm{CL}(\mathrm{L} / \mathrm{h})$ & $0.2978 \pm 0.0799$ & $0.1565 \pm 0.0015$ & $0.1681 \pm 0.0471$ & $0.059 \pm 0.001$ \\
\hline
\end{tabular}




\section{DISCUSSION}

CYP2C9, one of the major drug-metabolism enzymes in humans, constitutes approximately $20 \%$ of the hepatic cytochrome P450 enzyme expressed in humans (Takahashi and Echizen, 2001). Therefore, it plays a crucial role in the metabolism of the majority of drugs that are currently used in clinical practices. CYP2C9 polymorphisms have been reported to be associated with inter-individual pharmacokinetic variability in the metabolism of several drugs, including S-warfarin (Takahashi et al., 2003), diclofenac (Dorado et al., 2003), losartan (Dorado et al., 2003), phenytoin (Shon et al., 2002), and tolbutamide (Miners and Birkett, 1998). Furthermore, nucleotide substitution of the gene has been shown to induce a reduction in the catalytic activity of CYP2C9. Specifically, a heterozygous variant of CYP2C9*3 resulted in a $66 \%$ decrease in the clearance of oral S-warfarin in vivo, whereas the homozygote CYP2C9*3 showed a $90 \%$ decrease in the clearance of warfarin compared to the wild type genotype (Takahashi et al., 2003). As CYP2C9*3, which has an A 1075 to C substitution in exon 7, has been considered to be the major variant type in the Chinese population, we aimed to investigate its effects on meloxicam pharmacokinetics in a Chinese population.

To date, few studies have investigated the effects of CYP2C9 on the pharmacokinetics and pharmacodynamics of meloxicam. In a previous report, the genotype of CYP 2 C $9 * 1 / * 13$ was associated with decreased metabolism and increased pharmacodynamic effects of meloxicam in Korean subjects (Bae et al., 2011b). However, to the best of our knowledge, there are no reports concerning the relationship between CYP2C $9 * 3$ and pharmacodynamic effects of meloxicam in the Chinese population.

CYP2C9*3 is located in substrate recognition site 5 (SRS 5), resulting in structural changes that could reduce the activity of the enzyme (Lee et al., 2002). In the present study, the mean $\mathrm{CL} / \mathrm{F}$ value of meloxicam was significantly reduced in CYP2C9*3 variant genotypes compared with that of the wild type. Moreover, the AUC and Cmax showed significant reductions in CYP2C9*3 variant genotypes compared to the wild type.

The CYP2C9*3 allele causes alterations in back bone residues from Ile359 to Leu359, which results in protein restructuring such that the side chains block the substrate entrance (Funk et al., 2004); therefore, interactions between the enzyme and drugs are reduced. Here, CYP2C9*3 sequencing was performed to identify changes in the CYP2C9 coding region among all volunteers participating in this clinical study of meloxicam. The heterozygous variant of CYP2C9*3 $(1075 \mathrm{~A} / \mathrm{C})$ was observed in 2 of the 24 volunteers in the multi-dose group; no homozygous variant of CYP2C9*3 $(1075 \mathrm{C} / \mathrm{C})$ was detected. Significant decreases in AUC, Cmax, and CL were noted in the heterozygous variants compared with the wild type, demonstrating that an $\mathrm{A}$ to $\mathrm{C}$ substitution in exon 7 could lead to a reduction of the interaction between CYP2C9 and meloxicam. As the specific genotype variants of CYP2C9 may vary depending on the population and nationality of patients, it is necessary to identify potential associations between CYP2C9 genotypes and drug administration. Therefore, our study can provide helpful information regarding inter-individual pharmacokinetic variability in the Chinese population.

\section{REFERENCES}

Bae JW, Choi CI, Kim MJ, Oh DH, et al. (2011a). Frequency of CYP2C9 alleles in Koreans and their effects on losartan pharmacokinetics. Acta Pharmacol. Sin. 32: 1303-1308. 
Bae JW, Choi CI, Jang CG and Lee SY (2011b). Effects of CYP2C9*1/*13 on the pharmacokinetics and pharmacodynamics of meloxicam. Br. J. Clin. Pharmacol. 71: 550-555.

Chesne C, Guyomard C, Guillouzo A, Schmid J, et al. (1998). Metabolism of Meloxicam in human liver involves cytochromes P4502C9 and 3A4. Xenobiotica 28: 1-13.

Dorado P, Berecz R, Norberto MJ, Yasar U, et al. (2003). CYP2C9 genotypes and diclofenac metabolism in Spanish healthy volunteers. Eur. J. Clin. Pharmacol. 59: 221-225.

Funk M, Endler G, Freitag R, Wojta J, et al. (2004). CYP2C9*2 and CYP2C9*3 alleles confer a lower risk for myocardial infarction. Clin. Chem. 50: 2395-2398.

Lee CR, Goldstein JA and Pieper JA (2002). Cytochrome P450 2C9 polymorphisms: a comprehensive review of the invitro and human data. Pharmacogenetics 12: 251-263.

Miners J (2002). CYP2C9 polymorphism: impact on tolbutamide pharmacokinetics and response. Pharmacogenetics 12: 91-92.

Miners JO and Birkett DJ (1998). Cytochrome P4502C9: an enzyme of major importance in human drug metabolism. $\mathrm{Br}$. J. Clin. Pharmacol. 45: 525-538.

Schmid J, Busch U, Heinzel G, Bozler G, et al. (1995). Pharmacokinetics and metabolic pattern after intravenous infusion and oral administration to healthy subjects. Drug Metab. Dispos. 23: 1206-1213.

Shon JH, Yoon YR, Kim KA, Lim YC, et al. (2002). Effects of CYP2C19 and CYP2C9 genetic polymorphisms on the disposition of and blood glucose lowering response to tolbutamide in humans. Pharmacogenetics 12: 111-119.

Takahashi H and Echizen H (2001). Pharmacogenetics of warfarin elimination and its clinical implications. Clin. Pharmacokinet. 40: 587-603.

Takahashi H, Wilkinson GR, Caraco Y, Muszkat M, et al. (2003). Population differences in S-warfarin metabolism between CYP2C9 genotype-matched Caucasian and Japanese patients. Clin. Pharmacol. Ther. 73: 253-263.

van der Weide J, Steijns LS, van Weelden MJ and de Haan K (2001). The effect of genetic polymorphism of cytochrome P450 CYP2C9 on phenytoin dose requirement. Pharmacogenetics 11: 287-291.

Wang SL, Huang J, Lai MD and Tsai JJ (1995). Detection of CYP2C9 polymorphism based on the polymerase chain reaction in Chinese. Pharmacogenetics 5: 37-42.

Yoon YR, Shon JH, Kim MK, Lim YC, et al. (2001). Frequency of cytochrome P450 2C9 mutant alleles in a Korean population. Br. J. Clin. Pharmacol. 51: 277-280. 